\section{Telephone Loudspeakers for Group Conversations}

WE learn from the Soviet Union Year Book Press Service that a telephone loudspeaker to enable several persons to take part in a telephone conversation has been designed by the radio and telephone workshop of the Moscow Province post office administration. The apparatus consists of a loudspeaker and microphone instead of the ordinary handset. The microphone can be placed at a distance of three feet or more from the persons taking part in the conversation. If desired also, several telephone lines can be connected with the apparatus at the same time. It is operated with $110-120$ volts alternating current. Thirty of these new devices have already been made. It is not stated for what purposes they are intended. They might be useful for a teacher or lecturer who wanted to address several small classes simultaneously, although the classes were at considerable distances apart.

\section{Radcliffe Travelling Fellow in Astronomy}

Following nomination by the University of Oxford, the Radcliffe Trustees have elected Dr. H. Zanstra, of the University of Amsterdam, to the post of Radcliffe travelling fellow in astronomy for the three-year period commencing October 1937. Dr. Zanstra, formerly a National Research Fellow in the United States, has held university posts at Seattle, the Imperial College, and Amsterdam, and has carried out observational work at the Dominion Astrophysical Observatory, Victoria. $\mathrm{He}$ is best known for his theory of the origin of nebular luminosity, for his observational determination of the temperatures of the nuclei of planetary nebulæ, and for his investigations of the effects of radiation pressure on the stability of nebulæ.

\section{The Night Sky in April}

Berween April 1 and 30, the nights shorten in the latitude of London by nearly two hours. Summer Time comes into operation on April 18. New moon occurs on April 11 at $5 \cdot 2^{\mathrm{h}}$ and full moon on April 25 at $15 \cdot 4^{\mathrm{h}}$. If the evenings are clear, 'earthshine' on the moon may be observed from about April 13 until April 16. The planet Venus, which was conspicuous in the evening skies of last month, draws rapidly towards the sun's position until inferior conjunction takes place on April 18; next month it will be seen as a morning star. Mercury, which is usually rather a difficult object in the latitude of Great Britain for naked-eye observation, is at greatest eastern elongation $\left(20^{\circ} \mathrm{E}\right.$.) on April 20. The planet is in conjunction with Venus on April 7 at $15^{\mathrm{h}}$. On April 12 at $8^{\mathrm{h}}$ Mercury and Uranus are in conjunction, and at $12^{\mathrm{h}}$ on the same day there is a conjunction between Mercury and the moon which is then just over a day 'old'. Mars rises before midnight and is placed not far from Antares. Jupiter is a morning star, rising at about $21^{\mathrm{h}}$ in the middle of the month. Saturn, rising in the dawn, is not conspicuous. By $22^{\mathrm{h}}$ in mid-April, the winter constellations of Taurus, Orion, Canis Major and Canis Minor with their bright assembly of stars have nearly set in their entirety, whilst Vega has risen in the north-east, and Arcturus is about $2 \frac{1}{2}$ hours east of the meridian. The constellations on or near the meridian at this time offer several attractive objects for telescopic observation-the bright double stars of $\gamma$ Leonis (separation about $\left.4^{\prime \prime}\right)$, Castor $\left(4 \frac{1}{2}{ }^{\prime \prime}\right)$, $\xi$ Ursæ Majoris ( $\left.1^{\prime \prime}\right), \gamma$ Virginis $\left(6^{\prime \prime}\right)$, and $\alpha$ Canum Venaticorum $\left(20^{\prime \prime}\right)$. Messier 51 at R.A. $13^{\text {h }} 28^{\mathrm{m}}$, Dec. $+47 \cdot 4^{\circ}$ (epoch 1950), which is one of the best known spiral nebulæ, requires of course a large telescope and the photographic plate to resolve its structure. Messier 3 at R.A. $13^{\mathrm{h}} 40^{\mathrm{m}}$, Dec. $+28 \cdot 6^{\circ}$ is a notable globular cluster $18^{\prime}$ in diameter, whilst the "Owl" planetary nebulæ (Messier 97) is at R.A. $11^{\mathrm{h}} 12^{\mathrm{rn}}$, Dec. $55 \cdot 3^{\circ}$. The Lyrid meteors may be looked for on and about April 21, their radiant being near the star 104 Herculis. The northern sky should be scanned for appearances of the aurora-more particularly when a large sunspot is crossing the sun's disk.

\section{Announcements}

Mr. T. E. Harvey (Independent Progressive) has been elected M.P. for the Combined English Universities in the by-election caused by the death of Sir Reginald Craddock. Mr. Harvey was formerly an assistant in the British Museum and warden of Toynbee Hall.

Dr. H. J. Mulder, the distinguished Russian geneticist working with Prof. N. I. Vavilov, informs us that on March 15 he arrived at Valencia and was proceeding to Madrid for work with the Canadian blood transfusion unit. Dr. Muller states that he hopes to resume later the work in genetics which he had been carrying out in the Soviet Union, and which his colleagues there are continuing in his absence.

THE report of the Third Correlation Tour undertaken by the Soil Surveyors' Executive Committee has just been published by the Ministry of Agriculture, for England and Wales, and the Department of Agriculture for Scotland. The work of this committee is to correlate soil series examined and classified by soil surveyors in different parts of the country, and its third report refers particularly to the Bristol, Reading and West Midland Provinces and to Wales. Copies of the publication may be obtained gratis on application to the Ministry of Agriculture, 10 Whitehall Place, London, S.W.1.

THE Laboratory of Industrial Hygiene has been incorporated under the laws of the State of New York as a non-profit organization empowered to carry on scientific and industrial work in chemical, bacteriological and general public health problems, and to accept grants for definite scientific purposes. The president is Dr. William Hallock Park. The laboratory includes at the present time the following units : a certified milk laboratory under the direct supervision of Dr. Park, a vitamin-testing laboratory, a clinical diagnostic laboratory and chemical and bacteriological laboratories. 